\title{
A GENEALOGIA DA ÉTICA DE MICHEL FOUCAULT
}

\author{
Cesar Candiotto*
}

\begin{abstract}
RESUMO
A problematização da ética, observável principalmente nos últimos escritos de Michel Foucault, foi durante muito tempo insuficientemente analisada se comparada aos estudos em torno da analítica do poder e da arqueologia do saber. Ainda que, inicialmente, ela tenha sido explicitada a partir do estudo da conduta sexual dos homens livres da antiga Grécia e da Roma imperial, não é o aprofundamento desse domínio o que realmente interessa neste ensaio. Antes, importa o modo como a ética é singularmente situada em relação à moral e quais elementos fazem parte de sua constituição. Além disso, sustenta-se que a interrogação ética na investigação de Foucault objetiva a elaboração de um diagnóstico de nosso ser histórico e, com isso, se afasta de qualquer fundamentação da moral no pensamento contemporâneo.
\end{abstract}

Palavras-chave: Foucault. Genealogia. Ética. Moral. Subjetivação. Pensamento.

\begin{abstract}
The questioning on ethics, that one can principally observe in Foucault's last writings, was, during a long time, insufficiently analyzed in comparison with the studies about the analytic of power and archeology of knowledge. Although it has initially been made explicit, from the study on the sexual behavior of the ancient Greek and Imperial Roman citizens, it is not the deepening of this domain which really interests us in this essay. Rather, it is important to analyze how ethics is singularly situated vis-àvis the morals and what are the elements that constitute it. Furthermore, we maintain that the ethical question in Foucault's investigation aims at elaborating a diagnostic of our historical being; consequently, we keep at a distance of any moral foundation in contemporary thought.
\end{abstract}

Keywords: Foucault. Genealogy. Ethics. Morals. Subjectivity. Thought.

\footnotetext{
* Doutor em Filosofia pela Pontifícia Universidade Católica de São Paulo. Professor Adjunto do curso de Filosofia e do Programa de Pós-Graduação em Filosofia da Pontifícia Universidade Católica do Paraná. Coordenador do curso de especialização Ética em Perspectiva. E-mail: ccandiotto@gmail.com.br.
} 


\section{Status Quaestionis}

Há [...] alguma coisa profundamente ligada à nossa modernidade; afora as morais religiosas, o Ocidente só conheceu, sem dúvida, duas formas de ética: a antiga (sob a forma do estoicismo ou do epicurismo) articulava-se com a ordem do mundo e, descobrindo sua lei, podia deduzir o princípio de uma sabedoria ou uma concepção da cidade: mesmo o pensamento político do século XVIII pertence ainda a essa forma geral; a moderna, em contrapartida, não formula nenhuma moral, na medida em que todo imperativo está alojado no interior do pensamento e de seu movimento para captar o impensado. [...] Para o pensamento moderno, não há moral possível; pois, desde o século XIX, o pensamento já 'saiu' de si mesmo em seu ser próprio, não é mais teoria; desde que ele pensa, fere ou reconcilia, aproxima ou afasta, rompe, dissocia, ata ou reata, não pode impedir-se de liberar e de submeter. Antes mesmo de prescrever, de esforçar um futuro, de dizer o que é preciso fazer, antes mesmo de exortar ou somente alertar, o pensamento, no nível de sua existência, desde sua forma mais matinal, é, em si mesmo, uma ação - um ato perigoso (FOUCAULT, 1966, p. 338-339).

Foucault, em nota de rodapé, salienta que entre essas duas éticas "o momento kantiano constitui um ponto de juntura: é a descoberta de que o sujeito, enquanto racional, se dá a si mesmo sua própria lei que é a lei universal" (FOUCAULT, 1966, p. 339).

A citação e a nota anteriores indicam suficientemente o diagnóstico elaborado em 1966, no livro Les mots et les choses. Entre estóicos e epicuristas, a ordem da natureza constituía a referência a partir da qual eram articulados os princípios éticos; a partir de Kant, a referência é o processo de objetivação e universalização de máximas subjetivas e contingentes, elaborado pelo próprio sujeito enquanto sujeito racional. As leis morais decorrentes do teste do Imperativo Categórico são aquelas que qualquer ser racional se dá a si mesmo, quando quer conduzir-se moralmente, o que significa estabelecer uma conduta regrada. Contudo, a posição de Foucault é desconcertante quando afirma que na modernidade é impossível a formulação de qualquer moral, posto que: "todo imperativo está alojado no interior do pensamento e de seu movimento para captar o impensado". 
Quando menciona a modernidade, não está se referindo a Stuart Mill, Moore, Rawls, Habermas, Jonas e demais teóricos da ética normativa. Seu diagnóstico está alicerçado em pensadores da estirpe de Sade, Nietzsche, Artaud, Bataille e, de um modo mais discreto, Marx, Freud e o próprio Hegel. Nesse aspecto, o momento kantiano é considerado um "ponto de juntura" porque, entre a predominância nos antigos de um fundamento externo ao sujeito e a ausência moderna de qualquer fundamento, Kant constituíra o próprio sujeito a priori prático em fundamento da lei moral.

Passagens tão explícitas e ao mesmo tempo decididamente polêmicas como estas a respeito da ética não são recorrentes nas investigações de Foucault nos anos 1960. Além do já exposto, também se percebe uma inadvertida equivalência ou, no mínimo, uma indiferença explícita entre ética e moralidade. Esse detalhe toma importância haja vista que, posteriormente, Foucault estabelece diferenças semânticas entre esses termos. E, além disso, porque boa parte dos cursos, livros e demais manifestações que vão do final dos anos 1970 até sua morte, em 1984, são conhecidos como o momento da genealogia da ética, e não como genealogia da moral ao modo de um palimpsesto nietzschiano.

Se, de um lado, a perspectiva de Foucault toma distância de quaisquer sistemas éticos que proponham um fundamento válido e legítimo para a ação moral, tais como a natureza ou a razão; ainda que ela também tente se afastar das morais religiosas cujo fundamento é a Revelação; de outro lado, para entender minimamente a genealogia da ética foucaultiana é preciso situá-la em relação àqueles sistemas éticos e a essas morais religiosas.

Não se trata de encontrar normas de regramento das condutas a partir das quais são estabelecidos critérios de correção e obrigação (Kant, Rawls), tampouco propor princípios como os de "bem" e "felicidade" (Stuart Mill, Aristóteles), elevados a finalidades últimas a partir das quais são estabelecidas as avaliações éticas.

Foucault não está preocupado em como o indivíduo está obrigado a agir diante de certos princípios éticos ou como ele precisa se comportar em razão dos códigos morais. Não obstante, afirmar que ele não se preocupa com os princípios éticos ou códigos morais de conduta seria, no mínimo, uma conclusão apressada. 
$\mathrm{Na}$ verdade, sua investigação está insistentemente interessada no processo de constituição do sujeito. No caso dos últimos escritos, na constituição ética do sujeito, no sentido de perguntar pela relação singular que podemos criar em relação a nós mesmos diante dos códigos morais que nos são propostos culturalmente e dos princípios normativos que tendem a direcionar nosso agir. Importa qual é a atitude, qual é a modulação que elaboramos na nossa maneira de ser e de viver diante de tais códigos e princípios.

Significa que na investigação de Foucault importa muito mais tratar da ética como um campo de problematização do que como um âmbito normativo de fundamentação da ação moral.

Essa estratégia da problematização dos conceitos e dos objetos do pensamento é tributária daquela tradição moderna formada por pensadores como Sade, Nietzsche, Artaud, Bataille, Marx e Freud. Mas, paradoxalmente, Foucault não vai procurar saber o que esses pensadores, cada um a seu modo, produziram em termos de umanova interpelação da ética na modernidade. Ele contenta-se em utilizar suas estratégias para analisar um campo problemático específico. Provavelmente a estratégia que mais esteja explícita nessa análise, particularmente da ética, seja a da genealogia.

A genealogia é uma estratégia que renuncia encontrar a origem escondida de um objeto já dado ou sua forma invariável no decorrer da história, uma vez que dessa perspectiva inexistem uma origem essencial e uma unidade já constituída que possam explicá-lo. A “ética”, portanto, não é somente um objeto do conhecimento, mas principalmente um campo problemático que pode ser diagnosticado no seu processo de constituição em domínios específicos.

Foucault quer indicar que aquilo hoje transformado em princípio normativo foi antes um campo problemático cuja análise auxilia a propor um diagnóstico do presente, mas jamais a prescrever sobre o que e como devemos agir.

\section{A ética e seus campos de problematização}

Convém perguntar a Foucault em que aspectos o estudo da ética antiga (que na genealogia da ética foi recuada até o pensamento grego 
clássico) foi importante para diagnosticar seu modo de ser moderno. Em outras palavras, até que ponto o estudo da ética antiga tem sido importante para o diagnóstico da ética no presente, malgrado suas diferentes modulações?

$\mathrm{Na}$ investigação de Foucault, a ética foi problematizada enquanto tal somente nos últimos livros, cursos e demais escritos. A "Introdução" aos volumes II e III de Histoire de la sexualité (1984a, p. 7-31) é uma das passagens privilegiadas para compreender tal demarcação. Como é de conhecimento, em 1984 esses livros indicaram uma inflexão no pensamento de Foucault, ou, pelo menos, um estilo de escrita mais plano e liso, bem como um deslocamento estratégico para o canteiro histórico do pensamento antigo, ao contrário de seus livros anteriores. Foucault queria encontrar um momento na história do pensamento ocidental quando o sujeito não era a forma terminal de técnicas de decifração do eu, como forjadas no cristianismo a partir do século IV; e tampouco, constituído a partir da normalização das técnicas da disciplina e do biopoder, como observável no Ocidente europeu a partir do século XVII.

Foucault foi encontrar no pensamento clássico grego, nos manuais de aconselhamento e de conduta direcionados aos homens livres, uma maneira singular de problematização e especificidade da ética.

Ao contrário de boa parte das classificações dos sistemas éticos antigos, Foucault chama de moral o amplo campo da problematização da conduta. Afirma que em toda moral há, pelo menos, três elementos que se articulam com uma relativa autonomia: o código moral, que prescreve as regras de conduta; a moralidade dos comportamentos, que é a conduta que se pode medir por aquelas regras e a ética, caracterizada pelas modalidades de relação consigo estabelecidas pelo sujeito moral quando segue uma ou outra regra.

Se de um lado a ética, compreendida neste sentido peculiar, é praticamente ignorada, por outro, prevalece a ambiguidade em torno da definição de moral, uma vez que ela oscila entre sua identificação com o código moral e sua equivalência à moralidade dos comportamentos. Esta oscilação muito provavelmente seja explicada pela diferença de abordagem entre os estudiosos da moral.

Os filósofos da moral dedicam-se à história dos códigos morais, dos diferentes sistemas de regras e valores postos em funcionamento 
numa coletividade qualquer e propostos aos indivíduos por aparelhos prescritivos diversos, tais como a família, as instituições educativas, as igrejas etc. Estas prescrições proíbem, aconselham ou exigem condutas quando explicitamente formuladas em uma doutrina coerente; elas ainda estabelecem critérios de valores positivos ou negativos para condutas possíveis ao permitir comportamentos fugidios, quando transmitidas de maneira difusa. Portanto, moral no sentido de regras de conduta.

Os sociólogos da moral, por sua vez, definem a moral em função da moralidade dos comportamentos. Ela concerne ao comportamento real dos indivíduos, em que medida suas ações são conformes às regras e aos valores que lhe são propostos por meio das diferentes instâncias prescritivas. Moral aqui diz respeito às condutas que se podem medir àquelas regras, se elas obedecem ou resistem a uma prescrição, respeitam ou negligenciam um sistema de valores.

No entanto, uns e outros, filósofos da moral e sociólogos da moral não levam muito em consideração o terceiro elemento constitutivo da moral, denominado de "ética". Para Foucault, o importante na "ética" deixa de ser a regra moral ou a conduta que se pode medir em relação a ela pelo comportamento real do agente, mas sim seu modo de "conduzir-se" diante da prescrição da regra e a constituição como "sujeito moral" que isso demanda. Nesse sentido, a genealogia da "ética" é também uma história da "ascética", ou seja, a história da "maneira pela qual os indivíduos são chamados a se constituir como sujeitos de conduta moral" (FOUCAULT, 1984a, p. 41) pelo exame de si e pela transformação do seu modo de ser.

Pretende-se compreender, ao acompanhar a demarcação de Foucault, por que esse último elemento da moral tem sido tão negligenciado pelos historiadores e, em seguida, saber de Foucault como aquele elemento é enfatizado nos seus últimos escritos, de modo peculiar no domínio da conduta sexual?

Com respeito à primeira questão, a hipótese de Foucault é que os historiadores da moral não tratam das relações do indivíduo consigo mesmo nos seus compêndios ou as situam como um apêndice, porque elas frequentemente encontram-se associadas ao individualismo ou egoísmo ético. Foucault se afasta deste posicionamento quando identifica uma 
preocupação consigo inseparável da preocupação com os outros nos textos antigos dos gregos e romanos.

Em Histoire de la sexualité I: le souci de soi (1984b), ele faz uma diferença entre "atitude individualista", "valorização da vida privada" e "intensidade das relações consigo" (FOUCAULT, 1984b, p. 59) a fim de nuançar que as modalidades de "relação consigo" são inseparáveis da relação com os outros. A "atitude individualista" caracteriza-se pelo valor absoluto concedido ao indivíduo em sua singularidade e pelo grau de independência que lhe é atribuído em relação ao grupo ao qual pertence ou às instituições das quais depende; a "valorização da vida privada" referese à importância designada às relações familiares, às formas de atividade doméstica e ao campo dos interesses patrimoniais; quanto às "relações consigo", concernem às modalidades pelas quais o indivíduo é chamado a se tomar como objeto de conhecimento e campo de ação a fim de efetuar uma transformação do seu modo de ser mediante sua relação com os outros. Desse modo, as modalidades de relação de si para consigo não deixam de ter um caráter social.

\section{Os elementos constitutivos da ética}

A segunda questão, que mais nos interessa, consiste em saber de Foucault como as relações de si para consigo são tratadas nos seus últimos escritos, no caso específico do domínio da conduta sexual. Para isso, a genealogia de Foucault propõe uma abordagem diferente em relação àquela do código moral, que normalmente atua entre a obrigação e a proibição moral.

Nos dois últimos volumes de Histoire de la sexualité, ele sugere que se uma história da moral, no que concerne à conduta sexual, for considerada somente em função das proibições dos códigos, haveria pouca coisa a dizer sobre o que antecede o cristianismo primitivo.

Durante muito tempo, pensou-se que entre os antigos prevalecia a atitude da tolerância com respeito a determinadas condutas sexuais e que sua codificação rígida e proibitiva teria começado somente com o cristianismo. Pelo menos, quatro proibições morais quase não teriam mudado a partir da moral cristã: não fazer sexo além do necessário, não ter 
relações extraconjugais, não exercê-lo com pessoas do mesmo sexo e, até mesmo, abster-se da relação sexual.

Todavia, se tais condutas forem abordadas não pelo viés da proibição dos códigos de comportamento moral e sim pela problematização dos modos de "conduzir-se" diante deles, sua presença estende-se a toda a moral ocidental, do pensamento grego clássico até a modernidade, passando pela filosofia greco-romana e pelo cristianismo.

Significa que houve uma época no Ocidente quando tais condutas sexuais eram problematizadas sem que ainda fossem proibidas por uma moral religiosa ou informadas por sistemas de conhecimento, tais como os da biologia, da medicina e da psiquiatria, a partir do século XIX (Cf. DAVIDSON, 1988, p. 253). Trata-se da época da cultura greco-romana dos séculos I e II d.C. e da cultura grega clássica desde o século IV a.C. Por questão de delimitação, atemo-nos somente a esse último momento da cultura antiga no presente estudo.

De um lado, o cidadão grego do século IV a.C. tinha amplas liberdades no que concerne à conduta sexual, de modo que nenhum código social ou religioso o impedia de se relacionar com sua mulher, com seus escravos ou com outro homem; mas, de outro, proliferavam manuais de boa conduta, pequenos livros de conselho e de sabedoria prescrevendo-lhe caminhos de austeridade sexual.

A questão que se coloca é como identificar a razão de ser da preocupação com a conduta sexual numa cultura em que ela não é proibida ou reprimida. Foucault descobre que a razão pela qual os cidadãos livres sujeitavam-se à diminuição do ato sexual, à fidelidade conjugal e à abstinência do amor masculino era da ordem das modulações da relação consigo. Em outros termos, para que a existência de um varão fosse lembrada pelos seus descendentes era preciso que sua conduta fosse boa (regrada) e bela (exemplar). Não bastava ser livre, era preciso mostrar na prática que ele merecia tal status. Com esse intuito, era imprescindível fazer bom uso dos prazeres mediante uma liberdade estilizada. Moderarse e até mesmo abster-se daquilo que qualquer cidadão tinha direito: eis a expressão maior de sua liberdade.

Se, de um lado, em toda cultura ocidental as formas de problematização em torno da conduta sexual têm sido semelhantes, 
de outro, não significa que o modo de conduzir-se diante delas tenha permanecido sempre o mesmo. Há sempre "deslocamento, desvio e diferença de acentuação" (FOUCAULT, 1984b, p. 93) nas modalidades de relação consigo. $\mathrm{O}$ papel da genealogia consiste em diagnosticar tais diferenças, razão pela qual ela é denominada de "genealogia da ética" (FOUCAULT, 1994, p. 397).

Provavelmente, o aspecto mais relevante nos dois últimos volumes de História da sexualidade não seja a problematização da conduta sexual, mas, por meio dela, a análise histórica das modalidades de relação de si para consigo, das diferentes maneiras pelas quais os sujeitos tomam alguma parte de si próprios como centro de preocupação ética.

Seja considerado, por exemplo, o valor da fidelidade. A genealogia da ética não pretende investigar se as pessoas são ou não sempre fiéis ao seu cônjuge, ou ainda, estudar os diferentes códigos morais, sociais e religiosos que prescrevem a fidelidade sexual como tema de austeridade. Antes que uma análise do comportamento ou da proibição do código busca-se elaborar a história das diferentes maneiras pelas quais alguém se relaciona consigo diante do valor da fidelidade. Assim, alguém pode ser fiel levando em consideração quatro elementos constitutivos das relações consigo. $\mathrm{Na}$ verdade, são os quatro elementos constitutivos da ética, tal como a entende Foucault: a substância ética (ontologia), o modo de sujeição (deontologia), o trabalho ético (ascética) e a teleologia do sujeito moral (teleologia).

A substância ética. Diante de uma prática de austeridade, como a da fidelidade conjugal, o indivíduo precisa indicar qual a parte de si mesmo é a mais relevante para conduzir-se moralmente. Pode-se ser fiel apenas em função dos seus atos, abstendo-se das relações extraconjugais e satisfazendo sua esposa; mas, na prática da fidelidade, pode ser fundamental ainda combater o desejo que se tem por outra mulher e vigiar para não aceder a ele; enfim, o aspecto central da fidelidade pode ser a reciprocidade que se experimenta pelo cônjuge e a qualidade da relação que os une. A efetivação do ato, os movimentos do desejo e a qualidade dos sentimentos constituem três partes importantes de si mesmo.

Os modos de sujeição. Estabelecida a substância ética, convém indicar o modo de sujeição à regra da fidelidade, ou seja, como alguém se relaciona com ela e sente-se na obrigação de colocá-la em prática. Ele pode 
submeter-se à regra da fidelidade para ser reconhecido como pertencente a um grupo social que a valoriza, ou ainda por considerar-se o herdeiro de uma tradição espiritual, enfim, porque pretende dar à sua vida uma forma bela em virtude de uma escolha pessoal determinada.

A elaboração do trabalho ético. A elaboração do trabalho sobre si não consiste na adequação do comportamento à regra estabelecida, como na sociologia da moral, mas na transformação do indivíduo em sujeito moral de sua própria conduta mediante certas práticas de si. A fidelidade pode ser seguida por um controle regular da conduta, medindo a exatidão com que as regras são aplicadas; ela pode ainda impelir o indivíduo a propor para si próprio a renúncia total dos prazeres por meio de um combate permanente dentro de si; finalmente, o indivíduo pode transformar-se em sujeito de sua conduta por meio da decifração contínua dos movimentos do desejo.

A teleologia do sujeito moral. Trata-se do objetivo que se pretende alcançar por meio da elaboração do trabalho de si sobre si, ou seja, alcançar a condição de sujeito moral. A fidelidade conjugal impele um modo de conduzir-se cuja finalidade é o domínio de si como sujeito moral, o que pode ser observado nos manuais de conduta no pensamento grego do século IV a.C.; a fidelidade conjugal deve-se ainda ao propósito de um distanciamento radical do mundo circundante ou servir como meio para chegar à tranquilidade da alma e à imperturbabilidade em relação às paixões, como entre os estóicos; enfim, ela pode ser um meio para alcançar uma purificação que assegure a salvação após a morte, conforme sugere o cristianismo.

Histoire de la sexualité, volumes. II e III, é compreendida a partir das articulações históricas entre essas quatro modalidades de relação consigo. Se, por um lado, os limites dessa pesquisa não permitem aprofundar tais articulações, por outro, é possível diagnosticar a originalidade do elemento da ética e os ganhos teóricos para o conjunto das pesquisas de Foucault. Um deles é que a abordagem das modalidades de relação consigo na cultura antiga torna viável pensar numa constituição histórica do sujeito muito diferente de suas formulações anteriores nos escritos de Foucault.

$\mathrm{Na}$ arqueologia do saber de meados dos anos sessenta, o "homem"é um acontecimento histórico cuja emergência é demarcada por uma relação entre saberes, precisamente os saberes modernos da vida, do trabalho e da linguagem; na genealogia do poder dos anos setenta, o "indivíduo 
moderno" ele é o efeito da relação entre técnicas de saber e estratégias de poder; na genealogia da ética dos anos oitenta, as subjetividades são constituídas a partir de uma "relação consigo", relativamente independente das camadas arqueológicas do saber ou das matrizes capilares do poder.

Além disso, a identificação de uma região autônoma da ética permite apontar diferenças entre uma e outra moral onde eram observadas apenas continuidades, como destaca o próprio Foucault em 1983, numa conversa sobre a Histoire de la sexualité (FOUCAULT, 1994, p. 399-400).

É o caso das diferentes possibilidades culturais de relação consigo a partir da substância ética dos aphrodisia, ou seja, do conjunto composto pelo ato, pelo prazer e pelo desejo no domínio da conduta sexual. Foucault simplifica essas diferentes possibilidades por meio de quatro "fórmulas". Entre os gregos, o ato sexualé o elemento mais importante, sendo que o prazer e o desejo são seus subsidiários. Sobre o ato é que se deve exercer o controle, definir a quantidade, o ritmo, a oportunidade e as circunstâncias. Tem-se então a fórmula: “ato-prazer-(desejo)"(FOUCAULT, 1994,p. 400). O desejo é posto entre parêntese porque com os estóicos ele passa a ser condenado. Já na erótica chinesa (da qual Foucault não menciona sua periodização) o elemento a ser intensificado e prolongado tanto quanto possível é o prazer, ainda que o ato seja restringido e, no limite, prescindido. Teríamos assim a fórmula: "prazer-desejo-(ato)" (FOUCAULT, 1994, p. 400)1 ${ }^{1}$

Quanto ao cristianismo, acentua o desejo a fim de suprimi-lo até suas raízes; o ato é considerado neutro servindo, na maioria das vezes, somente para a procriação ou para a consumação do dever conjugal; por isso, precisa ser realizado sem que o prazer seja experimentado ou, pelo

1 Em Histoire de la sexualité I: la volonté de savoir, essa ênfase, denominada de ars erotica (arte erótica), é estendida para outras sociedades antigas, tais como a do Japão, da Índia, de Roma e dos árabe-muçulmanos. Na arte erótica, a verdade é extraída do prazer. O prazer é qualificado não por seu critério de utilidade ou por sua relação à lei do permitido e do proibido; antes, é conhecido como prazer dependendo de sua intensidade, de suas qualidades específicas e de sua duração. Trata-se de um saber cuja constituição tem a necessidade de permanecer em segredo, já que sua discursividade poderia diminuir sua eficácia e sua virtude. A arte erótica é transmitida de modo esotérico por um mestre, detentor dos segredos sobre os prazeres. Os efeitos dessa arte naquele que goza de seus privilégios é o domínio absoluto do corpo, um gozo único, o esquecimento do tempo e dos limites, o exílio da morte e de suas ameaças (FOUCAULT, 1976, p. 76-78). 
menos, anulando-o tanto quanto possível. Entretanto, se na prática o desejo precisa ser erradicado, teoricamente ele é muito importante, pois revela os movimentos da alma. A fórmula seria então: "(desejo)-ato-(prazer)" (FOUCAULT, 1994, p. 400). Enfim, a modernidade também acentua o desejo, não para suprimi-lo, mas para liberá-lo das instâncias repressivas que o sufocam; quanto ao ato, não tem muita importância e o prazer, não tem um estatuto definido.

Ora, uma filosofia da moral não estabelece tais diferenças e privilegia somente aquelas culturas em que o código moral e as instâncias de autoridade têm maior importância. Nesse caso, a constituição do sujeito moral é "quase jurídica" (FOUCAULT, 1984a, p. 42), na medida em que ele é reportado a um conjunto de regras ao qual precisa submeter-se. É verdade que a moral cristã não pode ser reduzida totalmente a esse modelo, posto que várias modalidades de relação de si para consigo podem ser identificáveis no seu percurso histórico. Entretanto, desde o século XIII até a véspera da Reforma Protestante do século XVI, houve uma codificação intensa e progressiva daquela moral ${ }^{2}$.

A genealogia da ética privilegia os momentos da história pouco tratados pelas filosofias da moral, a fim de descrever suas diferenças quanto às relações consigo. Não importa que os códigos sejam rudimentares, uma vez que a ênfase incide sobre os "exercícios pelos quais o próprio sujeito se dá como objeto a conhecer e as práticas que permitem transformar seu próprio modo de ser" (FOUCAULT, 1984a, p. 42). É o caso das éticas do estoicismo e do epicurismo, cujos direcionamentos estão mais voltados para as "relações consigo" e para a ascese pessoal do que para as codificações de conduta e sua separação entre o permitido e o proibido. Ainda que haja um respeito às leis e aos costumes estabelecidos no âmbito jurídico e social, o acento recai menos

2 Não existe apenas "a" moral cristã como uma estrutura monolítica refletida numa codificação jurídica. Além do período já mencionado, nos cursos do Collège de France e em alguns textos dos Dits et écrits, volume IV, Foucault estuda o momento em que o cristianismo introduz e transforma diversos elementos das tecnologias de si pagãs na vida monástica dos séculos IV e V d.C. Nessa moral, permanece ainda como preocupação as relações consigo, e não tanto a proibição dos códigos. A progressiva codificação da experiência moral começou a partir do surgimento da penitência tarifada no século VI, em seguida pela obrigatoriedade da confissão para todos os leigos segundo critérios de exaustividade, de continuidade e de regularidade, no século XI (FOUCAULT, 1999, p.161164; FOUCAULT, 1994, p. 295-308). 
no conteúdo e na aplicação daquelas leis do que na atitude que faz com que sejam respeitadas.

\section{A ética e a modernidade}

Em razão talvez de sua morte prematura, Foucault não chegou a problematizar essa ética da qual ainda fazemos parte. Curiosamente, como ocorreu com outros pensadores, ele faz um deslocamento monumental para a ética antiga. Como várias vezes fez questão de advertir, o redirecionamento para a ética antiga não pode ser compreendido como a busca de uma solução no passado para resolver os problemas enfrentados pela sociedade no presente. Não é possível encontrar soluções no passado, pois elas constituem o efeito de problemas que já não são nossos problemas. "Não encontramos a solução de um problema pela solução de outro problema colocado noutra época por pessoas diferentes" (FOUCAULT, 1994, p. 386). Pelo contrário, ao conhecer como os antigos problematizaram suas condutas, também nós podemos problematizar as nossas e a partir daí inventar e criar novas maneiras de ser e de viver, ainda que sempre provisórias.

Foucault ressalta que se a genealogia perguntar pelas formas de problematização da ética, principalmente no terreno da conduta sexual, elas praticamente não mudaram. A restrição da atividade sexual, sua proibição extraconjugal e sua rejeição entre parceiros do mesmo sexo persistem como formas de problematização. Mas se essa mesma genealogia perguntar pelas modalidades de relação de si para consigo que estas formas de problematização ensejaram no decorrer do pensamento ocidental, aí podemos identificar a pertinência da ética. Em diferentes camadas históricas desse pensamento - somente para lembrar que a genealogia também é precedida de uma arqueologia, nesse caso de uma escavação das maneiras de se conduzir - sempre foram propostas novas modalidades de ser e de viver.

Somente para exemplificar, dificilmente é aceitável na cultura hodierna que códigos morais, sociais ou religiosos intervenham na vida pessoal e íntima, na condição de regras a partir das quais a conduta deva ser medida (FOUCAULT, 1994, p. 386). Até mesmo os movimentos libertários têm dificuldade de fundar uma nova moral em razão do desconforto gerado pela tentativa de conduzir a vida íntima a partir de princípios universais e necessários. Geralmente, eles somente se atêm a justificações de conduta a 
partir de um pretenso conhecimento científico do eu, do desejo, do inconsciente e assim por diante. ${ }^{3}$ Ainda assim, torna-se difícil pensar que questões propriamente morais dependam unicamente de saberes científicos. Quando se estuda a experiência histórica singular dos gregos do século IV a.C., ou a cultura de si estoica e epicurista da época imperial romana, o que se observa não é a submissão da conduta ou a autenticação individual a partir de um saber já constituído e sim a utilização de diversas técnicas culturais que poderiam impelir a construção de uma outra perspectiva sobre o modo de conduzir-se.

Diante da ausência de um imperativo universal e da proposta da peculiaridade de um campo da ética a partir das relações consigo, quaisquer tentativas de explicação científica ou de codificação jurídica da moral passam a ser inoperantes. A ética, problematizada por ocasião do estudo do domínio da conduta sexual entre os antigos, pode ser o indicativo - não o fundamento - para a criação de novas estilísticas da existência.

Uma amostragem dessa possibilidade - alheia ao domínio da conduta sexual - diz respeito à menção feita por Foucault ao pensamento de Baudelaire, para o qual o êthos moderno implica numa atitude duplamente considerada: a que concerne à relação do indivíduo com a atualidade 4 e a que remete à sua "relação consigo".

3 Foucault enfatiza a importância desses movimentos libertários, como o feminismo, o movimento gay, etc., porém, considera-os insuficientes quando se trata de explicar as práticas de liberdade. O tema da libertação (sexual) pode levar à ideia de uma natureza ou de um fundo humano mascarado pelos processos históricos e sociais e alienado pelos mecanismos da repressão. Bastaria apenas romper com tais máscaras repressivas para que o homem reencontrasse sua origem e restaurasse uma relação plena consigo. Pelo contrário, trata-se de partir das práticas de liberdade e não das práticas de libertação. Antes que libertar nossa sexualidade de uma máscara repressiva, seria preciso libertarmo-nos da sexualidade e do próprio desejo. "Ce problème éthique de la définition des pratiques de liberté est, me semble-t-il, beaucoup plus important que l'affirmation, un peu répétitive, qu'il faut libérer la sexualité ou le désir" (FOUCAULT, 1994, p. 710).

4 A noção de atualidade surge de dois modos em Foucault. Um que procura sublinhar de que modo um acontecimento, por exemplo, aquele da partilha entre loucura e desrazão, engendra uma série de discursos, de práticas e instituições que se prolongam até nós. Atualidade, nesse caso, é o prolongamento da história no presente. Outro modo reporta a uma série de considerações sobre um texto de Kant, de 1784, Was ist Aufklärung?, no qual pela primeira vez o pensador alemão coloca filosoficamente a questão de sua própria atualidade, o que, segundo Foucault, seria o marco da passagem para a modernidade. Há duas linhas de análise a partir do texto de Kant. Primeira, quando Kant coloca a questão da pertença à própria atualidade, pretende interrogá-la como um acontecimento do qual teríamos que detectar o sentido e a singularidade, mas também a questão da pertença a 
A primeira implica "um modo de relação com respeito à atualidade; uma escolha voluntária que é feita por alguns; enfim, um modo de pensar e de sentir, um modo de agir e de conduzir-se que marca uma pertença ao presente como uma tarefa" (FOUCAULT, 1994, p. 568). Na perspectiva de Foucault, o próprio pensamento de Baudelaire é exemplo desta atitude na medida em que nele a atualidade é "o transitório, o fugitivo, o contingente" (FOUCAULT, 1994, p. 569). Imergir na atualidade consiste na extração de algo eterno que não esteja além ou aquém do instante presente, mas nele. Eis o que significa "heroicizar o presente" (FOUCAULT, 1994, p. 570), quer dizer ter a firme disposição de não desprezá-lo. Prestar atenção no presente consiste em imaginá-lo diferentemente do que ele é; e transformálo, captando-o naquilo que ele é.

A segunda perspectiva da atitude moderna consiste na ênfase concedida à relação consigo. Ser moderno significa ser artesão de si mesmo, tomar-se como objeto de uma dura e complexa elaboração mediante relações de si para consigo ascéticas. "O homem moderno, para Baudelaire, não é aquele que parte à descoberta de si mesmo, de seus segredos e de sua verdade escondida; é aquele que busca inventar a si próprio" (FOUCAULT, 1994, p. 571). O espaço dessa invenção é o da arte, mas não somente. Poderíamos incluir também a reinvenção das relações de amizade.

\section{Considerações finais}

Um dos desafios decorrentes da ética proposta por Foucault consiste em fazer da própria vida e pensamento obras de arte e objetos de

um "nós" correspondente a essa atualidade, ou seja, formular o problema da comunidade da qual fazemos parte. Segunda, retomar hoje a ideia kantiana de uma ontologia crítica do presente significa não apenas interrogar sobre o que funda o espaço de nosso discurso, mas esboçar seus próprios limites. Assim como Kant procura uma "diferença" entre o hoje e o ontem, também nós devemos procurar extrair da contingência histórica que nos faz ser o que somos, as possibilidades de ruptura e de mudança (REVEL, 2002, p. 5-6).

5 Aqui o presente é considerado sinônimo de atualidade. No entanto, também há diferenças entre um e outro nos escritos de Foucault. O presente é definido por sua continuidade história, aquilo que nos precede e que, no entanto, continua a nos atravessar. A atualidade, por sua vez, implica a ruptura com a rede epistêmica da qual fazemos parte, é a irrupção do "novo", do "acontecimento". Para a diferença entre presente, atualidade e acontecimento (EWALD, 1997, p. 203-204). 
elaboração cuidadosa. Talvez o caminho mais apropriado para esse árduo trabalho artesanal coincida com a tarefa fundamental da filosofia de nosso tempo: a "crítica permanente de nosso ser histórico" (FOUCAULT, 1994, p. 571). Lapidar quem somos para esculpir-nos diferentemente.

Nesse sentido, James Bernauer (1988, p. 315) indica que os quatro elementos da ética, observados por ocasião do estudo dos gregos, refletem também as quatro artes de interrogação que Foucault praticou em suas obras e que bem poderiam ser estendidas a uma ética do pensamento, preocupada com o diagnóstico do presente.

1) $\mathrm{O}$ que é necessário pensar hoje em oposição ao que a tradição considera como digno de ser pensado? Qual deve ser a substância do pensamento? 2) Quando examinamos este domínio, qual modo de apreensão deve-se buscar? Qual modo de subjetivação o pensador deve adotar? 3) Segundo qual metodologia a pesquisa deste modo de apreensão deve se realizar? A quais práticas de ascetismo ela deve se submeter a fim de poder pensar diferentemente? 4) Qual é o objetivo que perseguimos através da definição da substância, do modo de subjetivação e da prática do ascetismo? (BERNAUER, 1988, p. 315, tradução nossa).

Eis uma das possibilidades que a ética contemporânea poderia trilhar. Vale lembrar que com isso Foucault não pretende propor qualquer prescrição; somente quer indicar como ele próprio, na sua investigação intelectual, problematizou a relação do pensamento consigo mesmo em diferentes canteiros históricos. Sua interrogação ética, ainda que explícita somente ao final de seu trabalho, implicitamente norteou o conjunto de sua obra, que ele mesmo nomeou como uma história crítica do pensamento.

Essa crítica do pensamento, por sua vez, faz parte de uma genealogia, na medida em que esta parte nossa situação cultural, descreve sua diferença em relação ao passado, a fim retornar ao presente. Retorno, que não significa repetir o passado, mas provocar uma estranheza diante das familiaridades prontas e estimular o questionamento das evidências constituídas. A despeito disso, a ética proposta por Foucault tem como objetivo não somente causar uma estranheza em relação às nossas evidências e familiaridades, mas também incitar o artesanato do cotidiano do pensamento como tarefa indispensável diante das identidades forjadas pelos padrões comportamentais já estabelecidos. 


\section{Referências}

BERNAUER, J. Par-delá vie et mort. In: CANGUILHEM, G. (Org.). Michel Foucault philosophe: rencontre internationale. Paris: Seuil/Des Travaux, 1988. p. 302-327.

CANDIOTTO, C. Michel Foucault: ética e governo. In: SGANZERLA, A.; FALABRETTI, E.S.; BOCCA, F.V. Ética em movimento. São Paulo: Paulus, 2009. p. 219-230.

DAVIDSON, A. Arqueología, genealogía, ética. In: HOY, D.C. (Org.). Foucault. Tradução de Antonio Bonano. Buenos Aires: Nueva Visión, 1988.

EWALD, F. Foucault et l'actualité. In: FRANCE, D. et al. (Org.). Au risque de Foucault. Paris: Éditions du Centre Pompidou, 1997. p. 203-212.

FOUCAULT, M. Les anormaux. Cours au Collège de France, 1974-1975. Edição estabelecida sob a direção de François Ewald e Alessandro Fontana, por Valério Manchete e Antonella Salomoni. Paris: Gallimard/ Seuil, 1999. . Dits et écrits. Organizado por Daniel Defert e François Ewald. Paris: Gallimard, 1994. Vol. IV.

1976.

. Histoire de la sexualité I: La volonté de savoir. Paris: Gallimard, . Histoire de la sexualité II: L'usage des plaisirs. Paris: Gallimard, 1984a.

. Histoire de la sexualité III: Le souci de soi. Paris: Gallimard, 1984b.

. Les Mots et les choses: une archéologie des sciences humaines. Paris: Gallimard, 1966.

REVEL, J. Vocabulaire Foucault. Paris: Ellipses, 2002.

Data de registro:25/01/2012 Data de aceite:02/05/2012 